
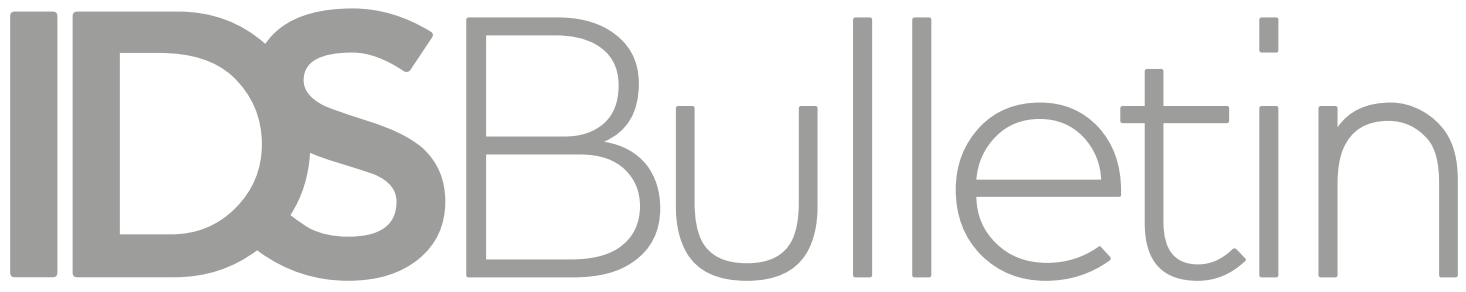

Transforming

Development Knouledge

Volume 50 | Number 2 | July 2019

\title{
THE POLITICAL \\ ECONOMY OF \\ FOOD
}

Editors Jody Harris, Molly Anderson, Chantal Clément and Nicholas Nisbett

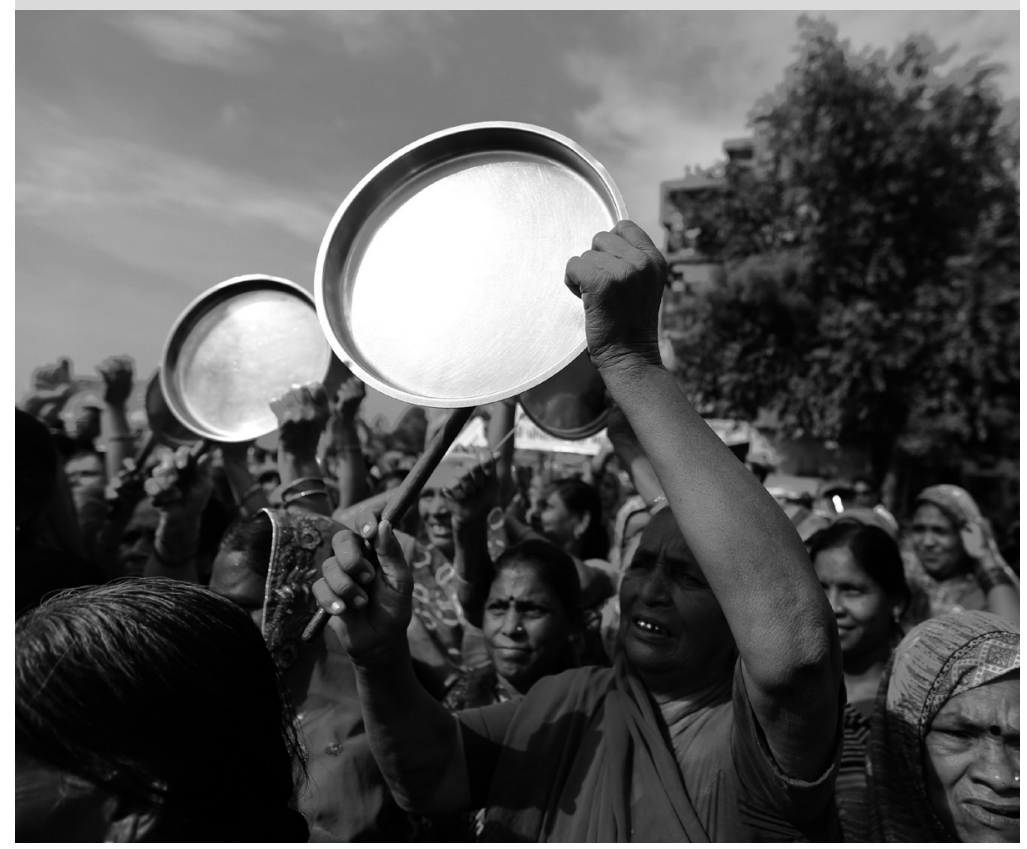


Notes on Contributors

Introduction: Valuing Different Perspectives on Power in the Food System

Molly Anderson, Nicholas Nisbett, Chantal Clément and Jody Harris

The Political Economy Approach to Food Systems Reform

Olivier De Schutter

Reflections on IPES-Food: Can Power Analysis Change the World?

Desmond McNeill

Envisioning New Horizons for the Political Economy of Sustainable Food Systems Jessica Duncan, Charles Z. Levkoe and Ana Moragues-Faus

Evidence-Based Policymaking in the Food-Health Nexus

Cecilia Rocha and Jody Harris

Purchasing and Protesting: Power from Below in the Global Food Crisis

Naomi Hossain and Patta Scott-Villiers

Agroecology and Food Sovereignty

Steve Gliessman, Harriet Friedmann and Philip H. Howard

Building a Sustainable Food City: A Collective Approach

Emily O'Brien and Nicholas Nisbett

\section{Power in the Zambian Nutrition Policy Process}

Jody Harris

Transforming Food Systems: The Potential of Engaged Political Economy 


\title{
Power in the Zambian Nutrition Policy Process ${ }^{+}$
}

\author{
Jody Harris ${ }^{1}$
}

\begin{abstract}
This article presents an example of a power analysis in the nutrition policy process in Zambia, using the 'power cube' framework. Here, nutrition policy priorities were found to have been shaped by a global epistemic community relying on the hidden and invisible power of technical language and knowledge to frame policy options which resonated with their own beliefs about malnutrition. Actors in the Zambian nutrition policy process worked largely in closed spaces of power, with policy options set and selected by small policy elites. Striking in their absence from either invited or claimed spaces of power were the malnourished themselves, or their communities or representatives, who did not have a clear voice in Zambia's nutrition policy process and therefore were without power. Further analysis of power is needed to better address glaring nutrition inequities and policy gaps such as those described in Zambia.
\end{abstract}

Keywords: nutrition, policy, power, Zambia.

\section{Introduction}

Malnutrition in its various forms continues to be a significant public health, economic, and equity problem in every country in the world: child stunting affects 150 million children (though falling); hunger affects almost 1 billion people (rising again after falling in recent decades); and overweight and obesity affect 2 billion adults and underpin more deaths in low-income countries than any other factor (and rising) (Development Initiatives 2018). Though the Sustainable Development Goals include targets on reducing the prevalence of both hunger and stunting (UN 2017), international organisations and national governments have struggled to create effective responses to these linked crises (Morris, Cogill and Uauy 2008; Bryce et al. 2008).

At country level, the politics of policy processes can be a significant hindrance to progressing a coherent response to these issues (Morris et al. 2008). There may be more pressing issues which governments choose to pursue (Pelletier et al. 2012); and there can be conflict among different framings of the issue between and within policy communities 
(Béné et al. 2019). Woven throughout these policy processes are power relations, but the interpersonal or institutional power which operates within these systems has been little explored (Nisbett et al. 2014). Drawing on emerging streams of work on nutrition in anthropology and political science, there have been calls for more explicit analysis of the role of power in the politics of nutrition policy (ibid.), which this work explores in the context of nutrition policy change in Zambia.

\section{Research approach}

This article emerged from a study of nutrition policy processes in Zambia aiming to investigate how and why certain international nutrition ideas and approaches have found their way into national nutrition policy and practice in Zambia (Harris 2019). Zambian nutrition policy and the community comprising its actors were explored over the course of a six-year engagement in the country (2011-17), with data collected through key informant interviews, document review, and social network analysis.

Zambian policy and programme documents relating to nutrition action were reviewed, with analysis including simple word counts to assess the prominence of different concepts, and narrative synthesis whereby commonalities and changes among the written content in different documents over time were identified and summarised. At the same time, 70 interviews with 61 different respondents over six years were undertaken, asking initially about the setting of agendas for nutrition following key global health agenda-setting frameworks (Shiffman 2007; Shiffman and Smith 2007), though interviews were open-ended and explored further topics that emerged in conversation. Respondents comprised international actors, some with links to Zambia $(n=17)$; national actors from a range of donor, United Nations, civil society, government, academia, and private sector organisations working on aspects of nutrition $(n=25)$; and local government and civil society actors in one district of Zambia where a key pilot project for nutrition was being undertaken $(\mathrm{n}=28)$.

Primary thematic analysis of interviews was through coding using NVivo 11 software (QSR International) with initial codes taken directly from the guiding framework but further codes derived in vivo from the data. Synthesis of these data streams involved bringing these different analyses together under an established framework covering different aspects of power (discussed below) to identify recurrent or important themes. This process was implemented in order to build a grounded explanation of how and why certain international nutrition ideas and approaches have found their way into national nutrition policy and practice in Zambia.

\section{Change in the Zambian nutrition policy process}

In Zambia, 40 per cent of children under age five are stunted, down from a high of 52 per cent in 2002; 6 per cent are wasted; and 6 per cent are overweight (CSO, MoH and ICF International 2014). 
Figure 1 Changing national nutrition policy focus over time

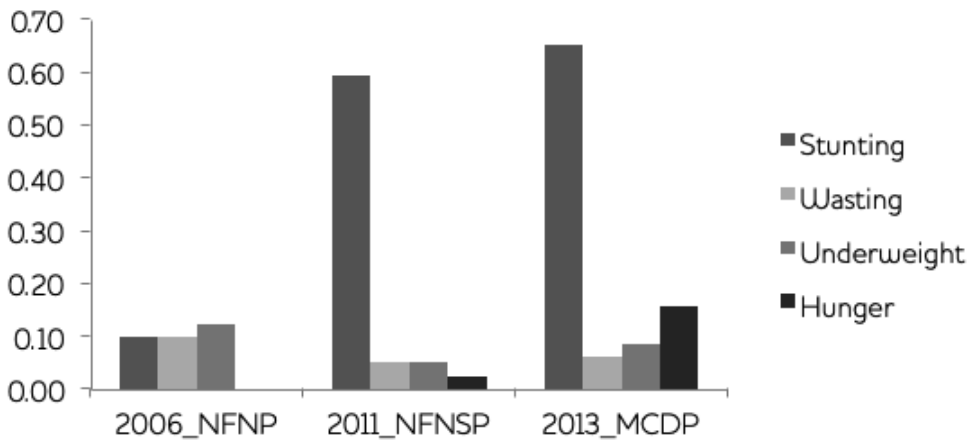

Notes Metric: mentions of four major nutrition outcome measures in written Zambian nutrition policy; Calculation: word count for each nutrition issue, divided by number of pages in the document.

Source Author's own.

Forty-five per cent of the population are classified as undernourished (hungry), particularly at certain times of the agricultural season, a figure that has been above 40 per cent for decades (von Grebmer et al. 2018). A recent micronutrient survey found significant deficiencies in multiple vitamins and minerals in women and children (those who were studied) (NFNC 2014). There are therefore multiple forms of malnutrition affecting the health and wellbeing of the Zambian population.

The document review for this study showed that there is a long history of action on aspects of malnutrition nationally, including in-patient and community treatment of acute wasting in children; a nationwide vitamin A supplementation programme; attention to nutrition in HIV care; and growth monitoring to detect underweight in children in a national network of clinics. Nutrition programmes have generally been undertaken in the health sector to promote health and childcare behaviour change, and treat clinical forms of malnutrition. Only recently were these disparate programmes underpinned by policy, with the 2006 National Food and Nutrition Policy (NFNP), subsequently operationalised in the 2011 National Food and Nutrition Strategic Plan (NFNSP), and the 2013 Most Critical Days Programme (MCDP). Content assessment of this written nutrition policy before and after 2008 (Figure 1) shows a clear increase in the number of mentions of stunting relative to other nutrition issues, suggesting that the idea of stunting significantly overtook other nutrition issues nationally over this time (Harris 2019). This is also clear from the content of the policies and strategies as they evolved over time, with the 2013 MCDP operationalising only the first of 11 strategic directions in the 2011 strategy document, focusing on stunting reduction. A majority of nutrition-related budgetary commitments also turned towards stunting reduction programmes over this time (de Kemp, Faust and Leiderer 2012). On multiple fronts, therefore, stunting has become the dominant 
concept in Zambian nutrition policy and practice, over and above other nutrition issues affecting the country.

Investigating this altered direction with interview respondents, it was clear that this change and consolidation around a single aspect of nutrition over the past decade was not felt to be of national genesis, but rather came from international actors working on nutrition in Zambia, in particular international non-governmental organisations (NGOs), donors, and the UN Scaling Up Nutrition (SUN) movement:

I think the global movement that has brought stunting to the fore... I do not think that it came necessarily from Zambia, saying we have got a challenge of stunting. I think it's because of the SUN movement and everybody now trying to focus on stunting. (National government key informant interview (KII) 2015_09)

Nutrition donors (notably DFID, UNICEF, and Irish Aid) have also described how they worked with the Zambian government to narrow the nutrition focus to stunting, given that the stunting issue was becoming the major focus of international efforts (Grütz, Sadlier and Brunet 2014).

Review of the international nutrition literature and the international interviews shows that indeed this turn to stunting originated in the international research and activist community. In 2008, a special issue of the influential international health journal The Lancet was published (The Lancet 2008), which drew together decades of global research on nutrition and is broadly credited (along with the advocacy of actors in the international nutrition community, and external shocks such as the 2008 food price crisis) with putting nutrition back on the international development agenda after many years of low interest and funding (Harris, forthcoming). This publication and others subsequently have advocated the metric of child stunting (significantly low height for a child's age) as the key measure of undernutrition in the world, because significantly stunted height is shown to correlate with limited brain development and poorer health and income in later life. Because of the multi-causal nature of stunting through food, health, and care determinants, researchers and advocates have suggested that interventions to reduce stunting need to explicitly engage multiple sectors outside of nutrition's traditional base in the health sector (Ruel and Alderman 2013). These core ideas of much of the international nutrition community - the primacy of stunting and the importance of multi-sectoral intervention - have since been integrated into the development community's international and country strategies.

In this research, the agenda-setting interventions to bring international ideas into national policy and practice that were mentioned most by respondents were direct advocacy and funding for the issue of nutrition and its possible solutions; the provision of technical assistance in the construction of policy; and the role of international evidence in 
framing nutrition. Evidence was a theme in interviews, with respondents citing the role of key research in shaping what makes it into policy, in particular widely promoted academic nutrition papers, and the availability and interpretation of nutrition data in the country. The key piece of evidence mentioned by respondents was The Lancet (2008) undernutrition series. The SUN movement has established both an advocacy arm (CSOSUN, a civil society organisation) and a funding arm in Zambia (the SUN donor fund, managed by the NGO Care International over the time of this research). Overall, the "what to do' advocacy message for nutrition has largely been supplied by the international community, focusing on stunting, through these advocacy organisations on the ground.

A particular stand-out position in this work, notable because it differed from other framings, was a respondent from an international donor who described various reports that were written by international consultants but that 'will come out as an NFNG [government] document' (International donor KII 2015_37). This illustrates most clearly the international influence on practice and policy that comes through technical assistance, and the framing of policy documents and ideas as national when in fact they are largely coming from international experts. In Zambia, international involvement with policy agenda setting and formulation was noted, particularly with UNICEF assistance and donor input in writing the original 2006 nutrition policy:

[The NFNP] was very consultative in that every partner put in what they felt would be their role, with the guidance of the NFNC of course, and a lot of along the way with a lot of [sic] international support at one point or another during the development of the document. (Government KII 2015_07)

\section{Power in the Zambian nutrition policy process}

Malnutrition in various forms are critical issues in Zambia. While hunger has been the historic preoccupation of the country, and a variety of nutrition programmes have been undertaken in the health sector, Zambia's alarming child stunting figures have recently been highlighted. Since Zambia's first national nutrition policy was created in 2006, subsequent strategy and operational documents and budgets have markedly changed their focus to prioritise child stunting over other nutrition issues in the country. Analysis shows that this change in direction was brought by the international community active in Zambian nutrition policy and practice, stemming from a turn to stunting within that community.

Given that international nutrition sits squarely within broader international development efforts, and given the central role of international development in the political life of most low-income countries, it follows that the concepts and narratives propagated by those working in the international development community are likely to have influenced how nutrition policy and action play out nationally. Those influencing Zambian national nutrition policy can be described 
Figure 2 Levels, spaces, and forms of power in Zambian nutrition policy processes

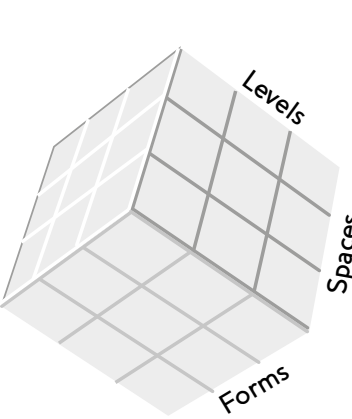

Levels

Global International donors; international NGOs; UN SUN movement

National Stunting coalition; government (NFNC) Local NGOs; local government

\section{Spaces}

Closed Knowledge generation; funding decisions Invited Policy discussions; programme decisions Claimed?

Forms

Invisible Internalised scientific and organisational cultures

Hidden Use of language; promotion of norms Visible Written policy and strategy; governance structures; budgets

Source Author's own analysis, adapted from Gaventa (2006).

as an epistemic community, understood as 'networks of professionals (possibly from different disciplines and backgrounds) with recognised expertise and competence in a particular domain and an authoritative claim to policy-relevant knowledge within that domain' (Haas 1992: 3). These epistemic communities apply their specialised knowledge and interpretations in providing information to decision-makers, offering input into policy decisions. Global epistemic communities bring their ideas and beliefs to national level, influencing different groups to share their framings.

Underlying many of the findings that have been summarised above is an implicit notion of power: power as holding and defining certain forms of knowledge, power to promote certain discourses, power as central to intervention in national policy processes, and power to define policy agendas. As the analysis for this study was undertaken, the topic of power emerged clearly as a factor influencing the Zambian nutrition policy process. To start to unravel the actors and interdependencies in the policy process, calls have recently been made for more explicit attention to the role of power in international nutrition, and in global health more broadly (Shiffman 2014; Shiffman and Smith 2007; Nisbett et al. 2014). A particularly useful conceptualisation of power in the policy process, which acknowledges a range of different definitions of power while maintaining analytical utility, is the 'power cube'. ${ }^{2}$ This threedimensional representation expresses the different forms that power might take, the different levels at which power dynamics can occur, as well as different spaces in which it might manifest (Gaventa 2006; Lukes 1974). These forms, spaces, and levels of power can be applied to assess power in the nutrition policy process in Zambia (Figure 2).

In this analysis, much power over the shaping of recent national nutrition policy is held by global epistemic communities with a presence in Zambia through international development organisations. 
At international level, this community shares broad beliefs about what should be done for nutrition, beliefs that are rendered visible through normative publications produced and disseminated by these groups. At the national level in Zambia, this community interacts with national government entities to bring these ideas into written policy and strategy.

Transfer of policy ideas through academic publications and subsequent technical assistance can be interpreted as closed - but visible - spaces of knowledge generation, where certain types of knowledge count most. The kinds of language used and the technical framing of nutrition within these debates may have limited the way that nutrition can be spoken about in different fora, and allowed for the promotion of certain norms above others, notably a scientific approach based on the findings of certain nutrition studies. This framing in turn stems from the invisible power exerted by the scientific culture that has shaped what is seen as valid knowledge in the field of nutrition, with evidence from field trials and economic analyses privileged in policy discourse, and organisational cultures and systems perpetuating a largely technical and bureaucratic approach to nutrition policy at the expense of more political or inclusive framings (Harris, forthcoming). Power in the nutrition policy process has therefore been generated by largely international groups through the hidden power of the technical language used in academic and policy debates; and the often invisible scientific cultures which shape what is seen as valid knowledge to feed into these debates.

The expertise of global epistemic communities is important and brings valuable insight from certain perspectives, but it is only part of a possible solution, and the types of action promoted are constrained by the forms of knowledge seen as valid in generating understanding of the issue and its solutions. Through these technical framings, most spaces in this analysis were maintained either closed to all but those sharing similar constructions of knowledge, or spaces where specific additional actors may be invited to participate in policy debates, with technical framings shaping the actions promoted. Notably, this work could not identify any claimed spaces of power in the nutrition policy process in Zambia; whether because of technical or scientific approaches closing spaces, or lack of engagement precluding invited spaces, national groups normally powerful in Zambian civil society (such as the churches and traditional leaders) are largely silent in the national nutrition policy debate. Those national NGOs that have participated have done so through CSOSUN, which has already taken its policy framing from the international community, and no policy actors mentioned national NGO groups as influential.

Also conspicuous in their absence - at the local or national level or in claimed or invited spaces of power - are the malnourished themselves, or the communities from which they come, who do not seem to have a clear voice in Zambia's nutrition policy process, and therefore find themselves without power. Communities such as the 
poor or malnourished are invoked by international groups in taking certain policy positions, particularly by NGOs with their presumed interaction with communities, and the UN and donors in advocating policies that they feel would be pro-poor. In practice, however, there is little participation of citizens or the malnourished and their framings in nutrition policy debates. The amount of political accountability owed to this group in the policy network map undertaken for this research (Harris 2019) makes them potentially powerful actors if they could be mobilised, however.

Appealing to and explicitly including this broad community constituency - whether framed as the electorate, citizens, or the malnourished - and including their own understandings and ideas of what is required to address nutrition issues in their communities, might present options that those working in the nutrition policy space had not previously considered. Nutrition policy research has so far only narrow engagement with theories of power, limiting our understanding of the role of power in these processes. Available work in this area suggests theoretical avenues including, but not limited to, the power cube (Hossain 2017; Nisbett et al. 2014), and suggests that a more nuanced understanding of power relations would support not only policymakers but also policy advocates (Blay-Palmer 2016). Internationally, the nutrition community is more aware of power imbalances when considering global food system issues; for example, the history of improper marketing of breastmilk formula, the undue influence of processed food manufacturers over obesity policy, or skewed political power in global trade agreements. There is currently too little empirical work analysing power in national nutrition policy processes to draw coherent parallels with the findings of this work, but there is a clear call for better understanding of power relations in multiple food and nutrition issues.

This study has presented a preliminary analysis of power in national policymaking for nutrition in Zambia, but further work is needed. Overall, these types of analysis allow us to put empirical flesh on the theoretical bones of a framework such as the power cube, and to systematically map aspects of power at work on a given issue; but also to see which aspects of power are absent and so suggest avenues to improve both equity in policy processes, and the policies themselves. This is necessary to better address glaring nutrition inequities and policy gaps such as those described in Zambia.

\section{Notes}

* Funding for this IDS Bulletin was provided by IPES-Food in furtherance of their aim to apply a political economy approach in understanding and reforming food systems.

+ This IDS Bulletin represents a collaboration between IDS and IPES-Food. Both organisations are committed to holistic, sustainable, democratic approaches to improving food systems, and to applying excellent research and political economy approaches in 
working towards these goals. We hope this IDS Bulletin represents the breadth of debate at the 2018 workshop we co-sponsored, on 'Political Economies of Sustainable Food Systems: Critical Approaches, Agendas and Challenges', and that it contributes to the sharing of knowledge in the name of sustainable and equitable food systems.

1 Jody Harris, Research Fellow, Institute of Development Studies, UK.

2 The power cube approach: www.powercubenet/.

\section{References}

Béné, C. et al. (2019) 'When Food Systems Meet Sustainability - Current Narratives and Implications for Actions', World Development 113: 116-30

Blay-Palmer, A. (2016) 'Power Imbalances, Food Insecurity, and Children's Rights in Canada', Frontiers in Public Health 4: 117

Bryce, J.; Coitinho, D.; Darnton-Hill, I.; Pelletier, D. and PinstrupAndersen, P. (2008) 'Maternal and Child Undernutrition: Effective Action at National Level', The Lancet 371.9611: 510-26

CSO, MoH and ICF International (2014) Zambia Demographic and Health Survey 2013-14, Rockville MD: Central Statistical Office (CSO), Ministry of Health $(\mathrm{MoH})$ and ICF International, www.dhsprogram.com/pubs/pdf/fr304/fr304.pdf (accessed 20 June 2019)

de Kemp, A.; Faust, J. and Leiderer, S. (2012) Synthesis Report: Between High Expectations and Reality: An Evaluation of Budget Support in Zambia (2005-2010), Stockholm: Sida, www.oecd.org/derec/sweden/ zambia.pdf (accessed 20 June 2019)

Development Initiatives (2018) 2018 Global Nutrition Report: Shining a Light to Spur Action on Nutrition, Bristol: Development Initiatives

Gaventa, J. (2006) 'Finding the Spaces for Change: A Power Analysis', IDS Bulletin 37.6: 23-33, https://bulletin.ids.ac.uk/idsbo/article/ view/898 (accessed 23 July 2019)

Grütz, S.S.; Sadlier, M. and Brunet, D. (2014) 'Reflections on the Role of Donors in Scaling Up Nutrition in Zambia from 2010 to 2013: Successes, Challenges and Lessons Learnt', in J. Harris, L. Haddad and S.S. Grütz (eds), Turning Rapid Growth into Meaningful Growth: Sustaining the Commitment to Nutrition in Zambia, Brighton: IDS

Haas, P.M. (1992) 'Introduction: Epistemic Communities and International Policy Coordination', International Organization 46.1: 1-35

Harris, J. (forthcoming) 'Narratives of Nutrition: Alternative Explanations for International Nutrition Practice'

Harris, J. (2019) 'Advocacy Coalitions and the Transfer of Nutrition Policy to Zambia', Health Policy and Planning 34.3: 207-15

Hossain, N. (2017) 'Inequality, Hunger and Malnutrition: Power Matters', in K. von Grebmer et al. (eds), 2017 Global Hunger Index: The Inequalities of Hunger, Washington DC, Bonn and Dublin: International Food Policy Research Institute, Welthungerhilfe and Concern Worldwide

Lukes, S. (1974) Power: A Radical View, Basingstoke and New York NY: Palgrave Macmillan 
Morris, S.; Cogill, B. and Uauy, R. (2008) 'Effective International Action against Undernutrition: Why has it Proven so Difficult and What can be Done to Accelerate Progress?', The Lancet 371.9612: 608-21

NFNG (2014) Zambia Food Consumption and Nutrition Survey Report, Lusaka: National Food and Nutrition Commission

Nisbett, N.; Gillespie, S.; Haddad, L. and Harris, J. (2014) 'Why Worry about the Politics of Childhood Undernutrition?', World Development 64: 420-33

Pelletier, D.L. et al. (2012) 'Nutrition Agenda Setting, Policy Formulation and Implementation: Lessons from the Mainstreaming Nutrition Initiative', Health Policy Plan 27.1: 19-31

Ruel, M. and Alderman, H. (2013) 'Nutrition-Sensitive Interventions and Programmes: How can they Help to Accelerate Progress in Improving Maternal and Child Nutrition?', The Lancet 382.9891: $536-51$

Shiffman, J. (2014) 'Knowledge, Moral Claims and the Exercise of Power in Global Health', International Fournal of Health Policy and Management 3.6: 297-99

Shiffman, J. (2007) 'Generating Political Priority for Maternal Mortality Reduction in 5 Developing Countries', American Fournal of Public Health 97.5: 796-803

Shiffman, J. and Smith, S. (2007) 'Generation of Political Priority for Global Health Initiatives: A Framework and Case Study of Maternal Mortality', The Lancet 370.9595: 1370-79

The Lancet (2008) 'The Lancet's Series on Maternal and Child Undernutrition: Executive Summary', The Lancet, www.thelancet.com/series/maternal-and-child-nutrition (accessed 20 June 2019)

United Nations (2017) UN Resolution 71/313 Annex: Global Indicator Framework for the Sustainable Development Goals and Targets of the 2030 Agenda for Sustainable Development, Geneva: United Nations General Assembly, https://unstats.un.org/sdgs/indicators/Global\%20 Indicator $\% 20$ Framework_A.RES.71.313\%20Annex.pdf (accessed 20 June 2019)

von Grebmer, K. et al. (2018) Global Hunger Index 2018: Forced Migration and Hunger, Bonn and Dublin: Welthungerhilfe and Concern Worldwide, https://reliefweb.int/sites/reliefweb.int/files/resources/ global_hunger_index_2018.pdf (accessed 20 June 2019) 